\title{
Numerical response of Nesidiocoris tenuis (Hemiptera: Miridae) preying on Tuta absoluta (Lepidoptera: Gelechiidae) in tomato crops
}

\author{
Juan A. SANCHEZ, Michelangelo LA-SPINA and Alfredo LACASA \\ Instituto Murciano de Investigación y Desarrollo Agrario y Alimentario (IMIDA), Dept. Biotechnology and Crop Protection, \\ C/Mayor, 1. La Alberca, 30150 Murcia, Spain; e-mails: juana.sanchez23@carm.es; cagitan2@hotmail.com; \\ laspinamichelangelo@gmail.com; alfredo.lacasa@carm.es
}

Key words. Hemiptera, Miridae, Nesidiocoris tenuis, Lepidoptera, Gelechiidae, Tuta absoluta, tomato borer, population dynamics, biological control, IPM, greenhouse

\begin{abstract}
Nesidiocoris tenuis (Reuter) (Hemiptera: Miridae) is an effective predator of pests of tomato crops and a promising biocontrol agent of Tuta absoluta (Meyrick) (Lepidoptera: Gelechiidae) in the Mediterranean area. The aim of this study was to determine the numerical response of $N$. tenuis to different levels of abundance of $T$. absoluta and its potential for controlling it when infesting tomato crops. The effects of infesting plants with either 0.2 or 2 larvae of $T$. absoluta and releasing either 2 or 0 adults of $N$. tenuis per plant were assayed in a complete factorial randomised-block design with 3 repeats in 12 greenhouse compartments in southern Spain. The population dynamics of the moth was similar in all compartments, with and without $N$. tenuis, but $T$. absoluta reached a lower absolute peak density in compartments with $N$. tenuis $(29.1 \pm 8.2$ larvae per leaf) than in those without them (44.5 \pm 19.4 larvae per leaf). The peak numbers of larvae of T. absoluta did not differ on the plants initially infested with 0.2 or 2 larvae. Nesidiocoris tenuis reached a maximum of $1.9 \pm 0.43$ and $3.0 \pm 0.4$ individuals per leaf in compartments in which low and high numbers of $T$. absoluta were initially introduced, respectively. The yield of tomatoes was higher in the treatments with $N$. tenuis than in those without, but the percentage of damaged fruit ( $>50 \%$ ) was similar. The slow numerical response of $N$. tenuis might have been due, among other things, to the poor establishment of this mirid due to the scarcity of prey. $N$. tenuis densities of about 0.2 individuals per leaf during the linear population growth phase of T. absoluta ( 0.5 to 3 larvae per leaf) did not prevent outbreaks.
\end{abstract}

\section{INTRODUCTION}

Species of zoophytophagous Dicyphine plant bugs (Hemiptera: Miridae: Bryocorinae) are among the most abundant and effective predators of pests of tomato [Solanum lycopersicum L. (Solanaceae)] crops (Alomar \& Albajes, 1996; Malausa \& Trottin-Caudal, 1996; Sanchez et al., 2003a, 2006; Castañé et al., 2004; Gillespie et al., 2007; Perdikis et al., 2008; Sanchez, 2008; Calvo et al., $2009,2012 a, b)$. The success of dicyphines as predators of pests of tomato crops is in part attributable to their adaptations for living on the surfaces of plants covered with non-glandular and/or glandular trichomes (Schuh \& Slater, 1995; van Dam \& Hare, 1998; Voigt et al., 2007; Voigt \& Gorb, 2010). On tomato crops in the Mediterranean area, Nesidiocoris tenuis (Reuter) (Hemiptera: Miridae) is one of the most abundant dicyphine species (Goula \& Alomar, 1994; Sanchez et al., 2003b). This omnivorous mirid behaves mainly as a carnivore when prey is abundant (Sanchez, 2008), since this leads to better performance than feeding only on plants (Urbaneja et al., 2005). At low prey densities, phytophagy increases, resulting in higher rates of flower abortion and the characteristic necrotic rings on stems and leaf petioles (Sanchez et al., 2006; Sanchez \& Lacasa, 2008; Arnó et al., 2009, 2010; Calvo et al., 2009; Sanchez, 2009; Castañé et al., 2011). As a predator, N. tenuis has catholic habits feeding on almost every small arthropod dwelling on tomato plants (Sanchez et al., 2006; Perdikis et al., 2008; Sanchez, 2008; Calvo et al., 2009); it is therefore not surprising that it included the South American tomato pinworm, Tuta absoluta (Meyrick) (Lepidoptera: Gelechiidae) as part of its diet when this new exotic pest started to infest Spanish tomato crops in 2006 (Urbaneja et al., 2007, 2009, 2012). The ability of predatory mirids to exploit such a wide range of different kinds of food in different trophic levels greatly influences the functioning of systems through their direct or indirect effects upon other species. For instance, at the primary producer level, plant feeding by $N$. tenuis triggers an overcompensation response in tomato plants, increasing productivity (Sanchez \& Lacasa, 2008; Sanchez, 2009), which might in turn, benefit strict phytophagous species and generate topdown-bottom-up effects (Ostfeld \& Keesing, 2000). As generalist predators, mirids, with a life cycle consisting of several instars of different sizes, and hence with different degrees of vulnerability to predation, may simultaneously be both intraguild predators and prey. For instance, N. tenuis may consume a high percentage of T. absoluta eggs parasitized by Trichogramma achaeae Nagaraja \& Nagarkatti (Hymenoptera: Trichogrammatidae) (Cabello et al. 2012). The presence of several species of predatory mirids on the same plant (Sanchez et al., 2003b) also increases the probability of intraguild interactions among species (Lucas \& Alomar, 2001, 2002; Lucas \& Rosenheim, 2011). In addition, the presence of predatory mirids as shared predators may mediate short and long term effects on pest population dynamics (Bompard et al., 2013). 
Following its introduction Tuta absoluta was controlled mainly by applying insecticides (Bielza, 2010), but the use of insecticides that are not very toxic for predatory mirids favoured the implementation of integrated pest management programs (Arnó et al., 2009; Mollá et al., 2011; Urbaneja et al., 2012). Early studies showed that both Macrolophus pygmaeus (Rambur) (Hemiptera: Miridae) and $N$. tenuis feed on all the development stages of T. absoluta and in tomato crops where these mirids are abundant the effect of the tomato borer on fruit is generally very low (Arnó et al., 2009; Mollá et al., 2009; Nannini, 2009; Urbaneja et al., 2009). However, these mirids show certain preferences, eating more eggs and small larvae than late instar larvae of T. absoluta (Arnó et al., 2009; Urbaneja et al., 2009). Other Dicyphini, such as Dicyphus errans (Wolff) (Hemiptera: Miridae) are also good potential biological control agents of T. absoluta (Ingegno et al., 2013). Mollá et al. (2011) report that the combined use of $N$. tenuis and Bacillus thuringiensis (Berliner) results in good control of T. absoluta. The release of predatory mirids in nurseries before transplanting, a technique used initially with $M$. pygmaeus (Lenfant et al., 2000), also gives good results with $N$. tenuis (Calvo et al., 2012a, b). Nesidiocoris tenuis released before planting are able to control Bemisia tabaci Gennadius (Hemiptera: Aleyrodidae) and T. absoluta, both individually and when the two pests are present (Calvo et al., 2012a).

Most of what is known about the response of $N$. tenuis to the abundance of T. absoluta comes from laboratory assays, in combination with chemical or biological control agents (e.g. B. thuringiensis or T. achaeae), or from pre-plantation strategies in which the introduction of T. absoluta into crop occurs when the predator is already abundant (Mollá et al., 2009, 2011; Nannini, 2009; Urbaneja et al., 2009; Cabello et al., 2012; Calvo et al., 2012a, b; Nannini et al., 2012). Currently, there is little information on the numerical response of $N$. tenuis preying on T. absoluta infesting tomato crops, and therefore, on the capacity of $N$. tenuis to reduce the abundance of $T$. absoluta without resorting to using other complementary control methods. This work aimed to determine the numerical response of $N$. tenuis to different levels of abundance of T. absoluta infesting tomato, in the absence of other control methods, and when this predator is released into a crop after the moth. This assay provides information about the net contribution of $N$. tenuis to regulating the abundance of T. absoluta.

\section{MATERIAL AND METHODS}

The assay was carried out in 12 greenhouse compartments each of $100 \mathrm{~m}^{2}$ at IMIDA research station in Dolores de Pacheco, Murcia (Spain), from 22 February to 27 June 2011. The compartments were built of polycarbonate, with meshed openings at the front and top for ventilation $(10 \times 14$ threads $/ \mathrm{cm})$. The temperature was controlled independently in each compartment by a Mithra clima System (Nutricontrol, S.L., Cartagena, Murcia); openings were activated automatically at $20^{\circ} \mathrm{C}$ and no heat or artificial lighting was provided. Temperature and Relative Humidity were recorded every minute. There were four rows of 20 tomato plants in each compartment; the distance between plants in a row was $0.5 \mathrm{~m}$ and $1 \mathrm{~m}$ between rows. Tomato seeds (Durinta variety, Western
Seeds Ltd, Narberth, UK) were planted on 12 January 2011 and seedlings 25-30 cm high were transplanted on 22 February 2011. Plants were grown in soil, and watered and fertilized when needed by drip irrigation.

The experiment had a complete factorial randomised-block design, with $T$. absoluta introduced at two rates $(0.2$ and 2 third instar larvae per plant) and $N$. tenuis at two levels (presence/absence). Each treatment was repeated three times. Half of the $T$. absoluta larvae ( 0.1 or 1 per plant) were introduced on 31 March (week 1$)$ and the other half ( 0.1 or 1 per plant) on 6 April 2011. One adult of Nesidiocoris tenuis was released per plant on week 3 and 4 (15 and 20 April 2011) (sex ratio 1:1). Using similar numbers Calvo et al. $(2009,2012 b)$ report satisfactory control of whitefly on tomato. Tuta absoluta and $N$. tenuis were originally collected from field cultivated tomatoes at Aguilas (Murcia) and reared on tomato plants and Ephestia kuehniella Zeller (Lepidoptera: Pyralidae) eggs in temperature-controlled growth chambers at $25^{\circ} \pm 2^{\circ} \mathrm{C}$ and $60-70 \%$ RH.

Nesidiocoris tenuis (nymphs and adults) and T. absoluta (larvae, pupae and adults) were counted weekly on every leaf of each plant from week 1 until week 6 . Thereafter, the insects were counted on the first, second and third leaf and then every third leaf down to the bottom of the plant. The number of leaves on each plant was also recorded. Necrotic rings were counted weekly on the first, second and third leaves on the apex of each plant. Twenty tomato plants selected at random in each compartment were sampled from week 1 to week 8 , and 15 plants from week 9 to week 14. The sampling effort was reduced after weeks 6 and 9 because T. absoluta and $N$. tenuis densities were high and the reduction in sample size involved no great loss in the precision of the estimates (Sanchez, 2011). Tuta absoluta larvae were counted by illuminating the underside of the tomato leaves with a HQ ultra bright LED torch (Starlite, Shanghai Xingyi International Co., Ltd., Shanghai, China). Tomatoes were harvested on 31 May, and 6, 13 and 27 June 2011 (weeks 10, 11, 12 and 14, respectively). In each compartment, the total yield was weighed at each harvest and 100 ripe tomatoes were scored for the presence of T. absoluta damage.

The bottom leaves of tomato plants in all the compartments were treated with powdered sulphur on 15 March 2011 to prevent fungal diseases and kill Aculops lycopersici (Massee) (Acari: Eriophyidae). Acetamiprid (20\%) was sprayed on 17 June (week 12) in those compartments where $N$. tenuis was not released to prevent this mirid from becoming established. Acetamiprid has little effect on T. absoluta (Braham \& Hajji, 2012), but is very toxic for the mirid pest Lygus rugulipennis Poppius (Hemiptera: Miridae) (Fitzgerald \& Jay, 2011) and predatory mirid Deraeocoris brevis (Uhler) (Hemiptera: Miridae) (Kim et al., 2006).

The effect of the numbers of $N$. tenuis and T. absoluta introduced, and the significance of the interaction term, on the average number of T. absoluta larvae, pupae and adults and N. tenuis (nymphs + adults) per leaf recorded in the different treatments was analysed using a two-way ANOVA. On each date, the number of insects on leaves was averaged for each plant and then for each compartment. Using ANOVA, the number of necrotic rings was compared in the compartments in which the plants were each infested with either 0.2 or 2 third instar larvae of T. absoluta. Data on the numbers of $N$. tenuis and necrotic rings were transformed using the natural logarithm of $(x+1)$ to correct for heteroscedasticity. The temporal pseudoreplication due to the weekly sampling and the spatial variability due to compartments were accounted for by including week of sampling and compartment in the Error term of ANOVA (Crawley, 2007). Cross correlation analyses were performed between the $N$. tenuis (nymphs plus adults) and T. absoluta (larvae) time series. Cross correlation was 


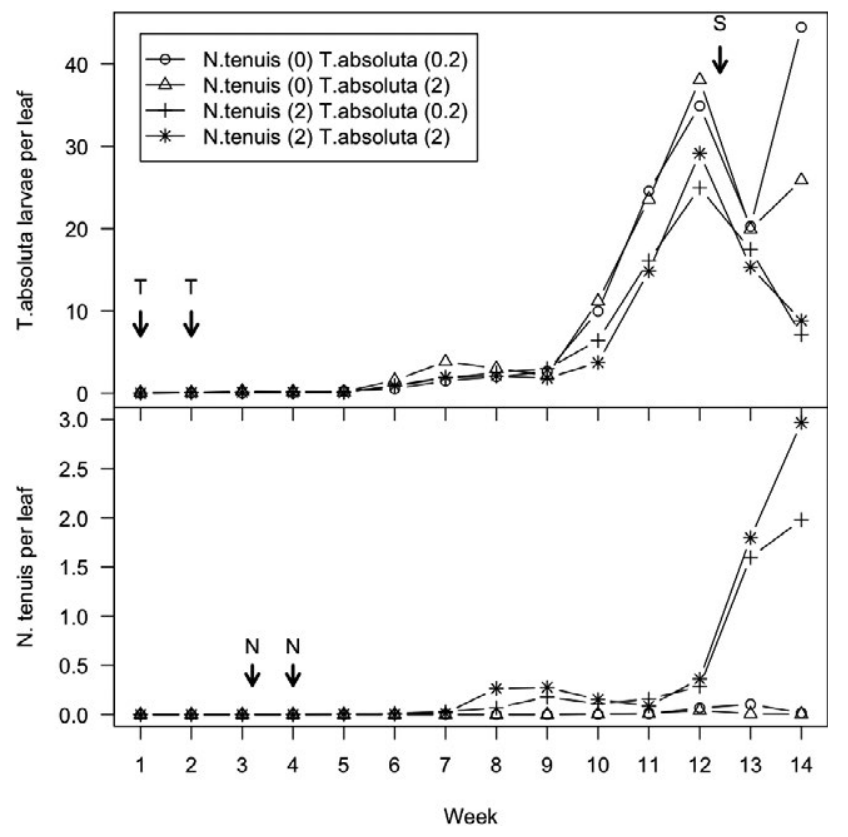

Fig. 1. Numbers of T. absoluta larvae (upper graph) and $N$. tenuis (lower graph) per tomato leaf in the different treatments. Numbers in brackets in the legend indicate the total number of individuals of each species released per plant. $\mathrm{X}$ axis is the number of weeks after the infestation of the tomato plants with T. absoluta. Arrow (T), release of T. absoluta; Arrow (N), release of $N$. tenuis; Arrow (S), sprayed with acetamiprid to kill N. tenuis in the greenhouse compartments in which this mirid was not released.

also performed on the $N$. tenuis and Dicyphus hesperus Knight (Hemiptera: Miridae) versus Trialeurodes vaporariorum Westwood (Hemiptera: Aleyrodidae) time series, using experimental data from previously published works (Sanchez, 2008; Sanchez et al., 2003a). Counts of $N$. tenuis nymphs and adults on entire plants were plotted against time to reveal the success of establishment and the population structure of the mirid after the releases. In the weeks when $N$. tenuis was counted on alternate leaves, the number of individuals per plant was estimated by multiplying the average number of insects per leaf by the total number of leaves on a plant. Total yield and the proportion of damaged fruit were compared among treatments using ANOVA. All the statistical analyses were performed using R (R Development Core Team, 2008).

\section{RESULTS}

The number of T. absoluta larvae remained very low in all the treatments during the five weeks following their in-

TABLE 1 . Summary of the cross correlation analysis between $N$. tenuis and T. absoluta time series recorded in tomato greenhouse compartments in which the tomato plants were initially infested with either a low (0.2 larvae per plant) or high (2 larvae per plant) number of T. absoluta. Pearson's correlation index; Lag in weeks; df, degrees of freedom.

\begin{tabular}{ccccccc}
\hline T. absoluta & Compartment & Lag & Index & t-Student & df & P-value \\
\hline 0.2 & 1 & 1 & 0.831 & 5.0 & 11 & $<0.001$ \\
0.2 & 2 & 1 & 0.973 & 14.0 & 11 & $<0.001$ \\
0.2 & 3 & 2 & 0.991 & 24.5 & 10 & $<0.001$ \\
2 & 1 & 2 & 0.998 & 56.2 & 10 & $<0.001$ \\
2 & 2 & 2 & 0.988 & 19.9 & 10 & $<0.001$ \\
2 & 3 & 2 & 0.954 & 10.1 & 10 & $<0.001$ \\
\hline
\end{tabular}

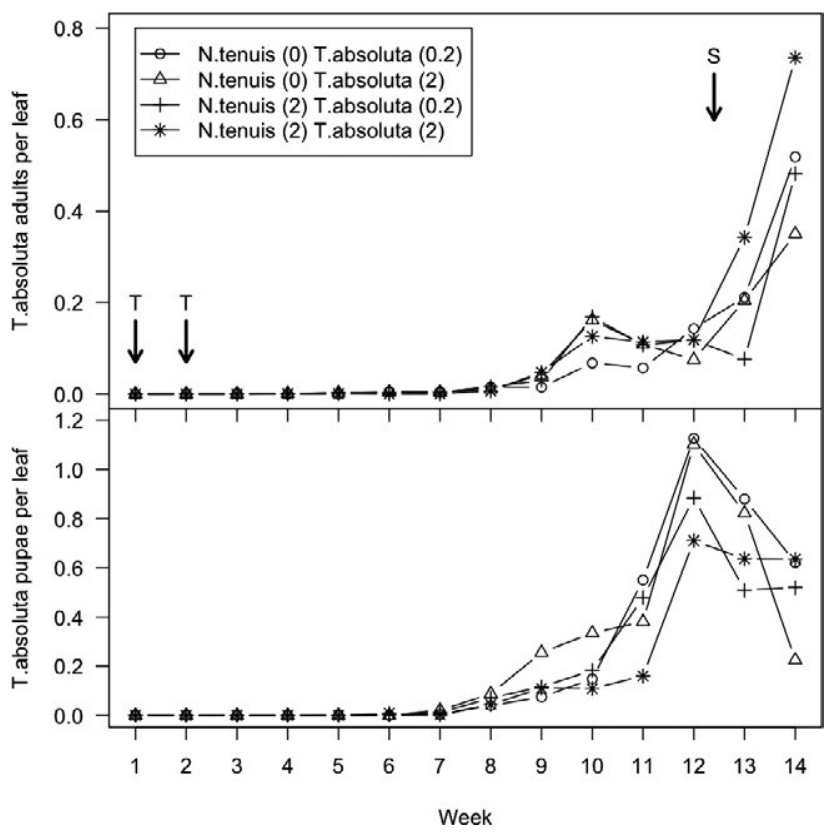

Fig. 2. Numbers of T. absoluta adults (upper graph) and pupae (lower graph) per tomato leaf in the different treatments. Numbers in brackets in the legend indicate the total number of larvae released per plant. $\mathrm{X}$ axis is the number of weeks after infestation of the tomato plants with $T$. absoluta. Arrow (T), indicates time of release of T. absoluta; Arrow (S), sprayed with acetamiprid to kill $N$. tenuis in the compartments in which this mirid was not released.

troduction (Fig. 1). From week 5 (following the first introduction of $T$. absoluta) to 9 there was a linear population increase, with similar T. absoluta densities in all the treatments, ranging from $0.14 \pm 0.03$ to $3.00 \pm 0.76$ (average $\pm \mathrm{SE}$ ) larvae per leaf in compartments without $N$. tenuis, and from $0.06 \pm 0.02$ to $2.97 \pm 1.17$ larvae per leaf in compartments with $N$. tenuis (Fig. 1). From week 9 to week 12 there was an exponential increase in T. absoluta numbers, with lower T. absoluta densities in treatments in which $N$. tenuis was present than in those where it was absent (Fig. 1). Tuta absoluta reached a lower absolute peak density in compartments with $N$. tenuis $(29.1 \pm 8.2$ T. absoluta larvae per leaf) than in those without $N$. tenuis $(44.5 \pm 19.4$ T. absoluta larvae per leaf) (Fig. 1). The number of T. absoluta larvae was significantly lower in the treatments with $N$. tenuis than in those without $(\mathrm{F}=9.57$; d.f. 1,$8 ; \mathrm{P}=0.015)$. The number of T. absoluta in the treatments with $N$. tenuis decreased gradually from week 12 , while in the treatments

TABLE 2. Summary of the cross correlation analysis between $N$. tenuis and $D$. hesperus versus whitefly nymph abundance on tomato in greenhouses using previously published data (Sanchez, 2008; Sanchez et al., 2003a). Pearson's correlation index; Lag in weeks; df, degree of freedom.

\begin{tabular}{ccccccc}
\hline Species & House & Lag & Index & t-Student & df & P-value \\
\hline N. tenuis & 1 & 4 & 0.978 & 13.3 & 8 & $<0.001$ \\
N. tenuis & 2 & 4 & 0.954 & 9.0 & 8 & $<0.001$ \\
N. tenuis & 3 & 4 & 0.940 & 7.8 & 8 & $<0.001$ \\
N. tenuis & 4 & 4 & 0.849 & 4.6 & 8 & $<0.01$ \\
D. hesperus & 1 & 5 & 0.964 & 12.1 & 11 & $<0.001$ \\
\hline
\end{tabular}




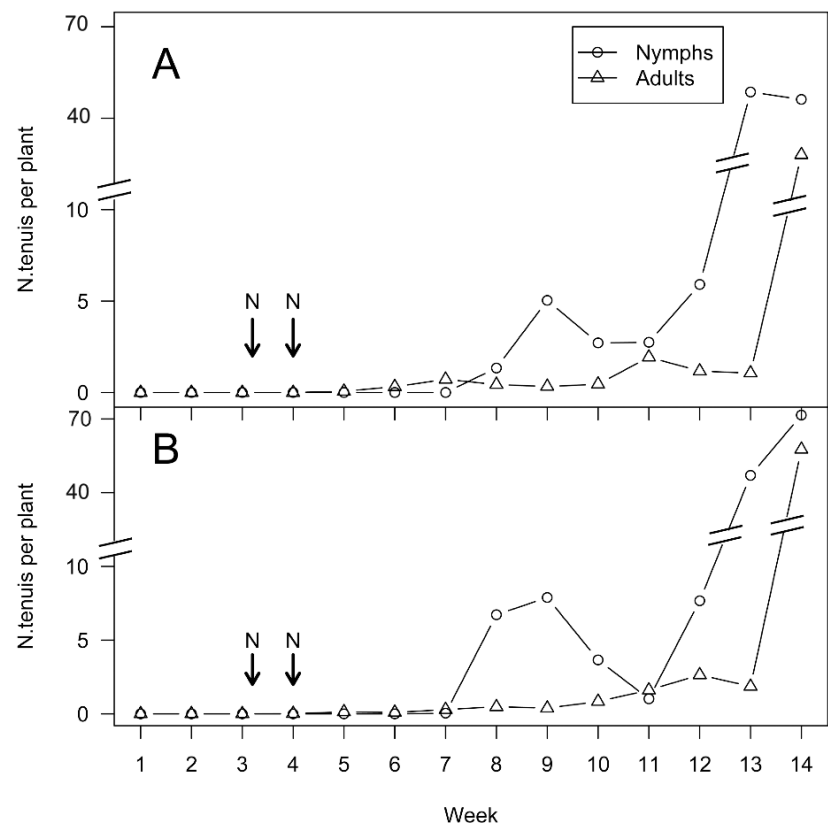

Fig. 3. Numbers of $N$. tenuis nymphs and adults per tomato plant in greenhouse compartments in which the plants were each infested with either a low (0.2 larvae per plant) (A) or a high number (2 larvae per plant) of T. absoluta (B). X axis is the number of weeks after the infestation of the tomato plants with T. absoluta. Arrow $(\mathrm{N})$ indicates the time of release of $N$. tenuis. The two parallel lines indicate a change in the scale.

without $N$. tenuis the numbers continued to increase until the end of the assay (week 14) (Fig. 1). The population dynamics of $T$. absoluta in the treatments infested initially with either a low or high number of $T$. absoluta were similar (Fig. 1), and no significant differences were found in the number of larvae in these two treatments $(F=0.250$; d.f. $1,8 ; \mathrm{P}=0.631)$. The interaction between $N$. tenuis and $T$.

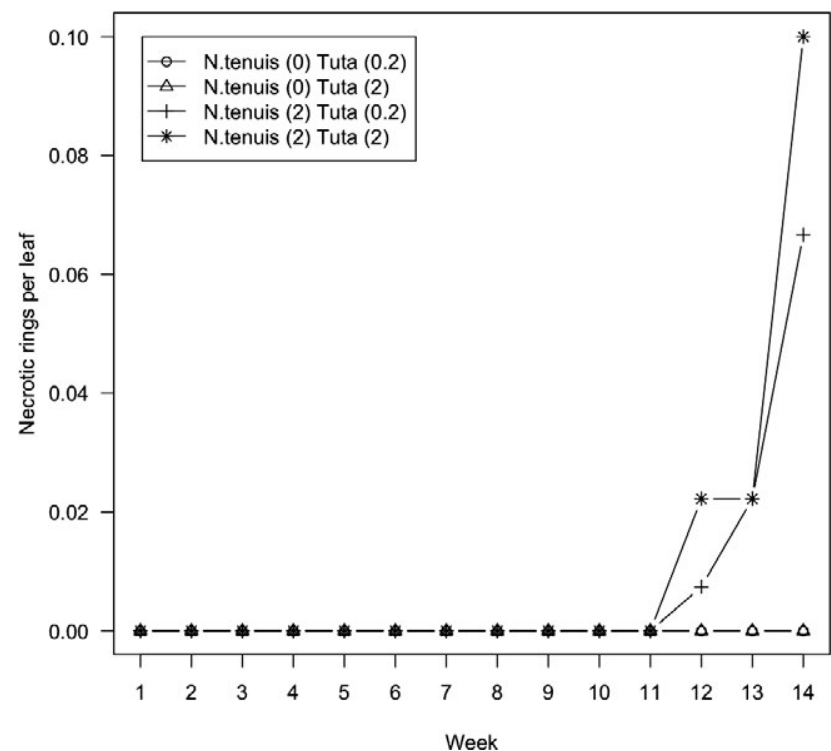

Fig. 4. Incidence of necrotic rings produced by $N$. tenuis recorded in the different treatments. $\mathrm{X}$ axis is the number of weeks after the infestation of the tomato plants with T. absoluta. Numbers in brackets in the legend indicate the total number of individuals of each species released per plant.

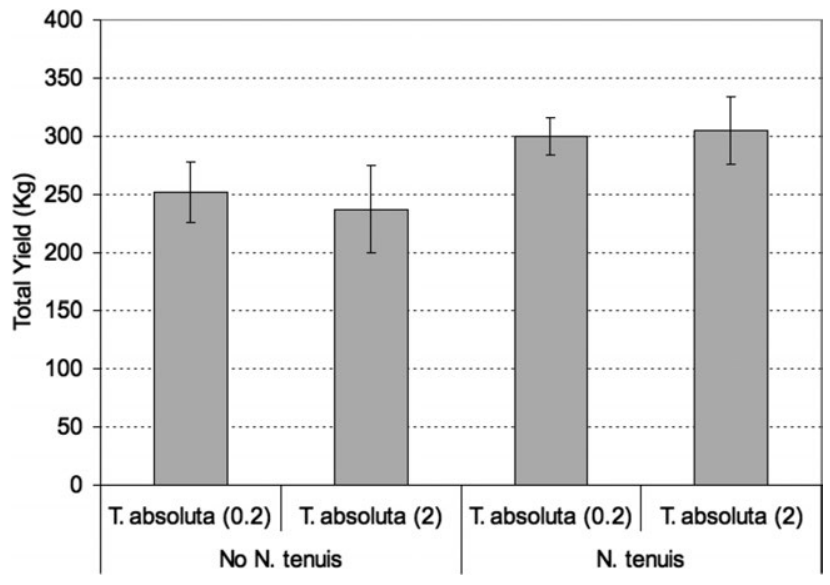

Fig. 5. Total yield $(\mathrm{kg})$ of tomatoes in the greenhouse compartments with and without $N$. tenuis and initially infested with either 0.2 or 2 larvae of $T$. absoluta per plant.

absoluta introduction rates was not significant $(\mathrm{F}=0.369$; d.f. 1,$8 ; \mathrm{P}=0.560)$. In the compartments with no $N$. tenuis releases, there was a reduction in the number of $T$. absoluta after treatment with acetamiprid (Fig. 1). The trend in the numbers of adults and pupae of T. absoluta was very similar to that of the larvae (Fig. 2). The first T. absoluta adults were generally observed between week 3 and 5 , and the first pupae between week 5 and 7 . In all the treatments, the average number of adults and pupae per leaf up to week 7 was below $0.004 \pm 0.002$ and $0.021 \pm 0.013$, respectively. Thereafter, the density of adults and pupae increased exponentially to reach a peak between $0.350 \pm 0.002$ and $0.736 \pm 0.087$ adults, and $0.884 \pm 0.292-1.128 \pm 0.135 \mathrm{pu}-$ pae per leaf on week 14 and 12, respectively (Fig. 2). There were no significant differences in the numbers of adults and pupae in the treatments with low and high initial infestations with $T$. absoluta (Adults, $\mathrm{F}=0.715$; d.f. 1,$8 ; \mathrm{P}=$ 0.422 . Pupae, $\mathrm{F}=1.795$; d.f. 1,$8 ; \mathrm{P}=0.217)$. The number of adults and pupae of T. absoluta were generally lower in treatments with $N$. tenuis (Fig. 2), although, no significant differences $(\mathrm{P}>0.05)$ were found between treatments with and without this mirid (Adults, $\mathrm{F}=3.736$; d.f. 1, 8; $\mathrm{P}=0.089$. Pupae, $\mathrm{F}=5.155$; d.f. 1,$8 ; \mathrm{P}=0.053)$.

In the compartments where $N$. tenuis was released, the number of $N$. tenuis (nymphs + adults) up to week 6 in both the low and high initial infestations of $T$. absoluta treatments was below $0.030 \pm 0.010$ and $0.014 \pm 0.020$ individuals per leaf, respectively (Fig. 1). From week 7 to week 11, N. tenuis in treatments with low introductions rates of T. absoluta ranged between $0.067 \pm 0.031$ and $0.285 \pm 0.112$ individuals per leaf. In treatments with high introduction rates of T. absoluta, $N$. tenuis ranged between $0.265 \pm 0.077$ and $0.362 \pm 0.165$ individuals per leaf (Fig. 1). Between week 11 and 14 the number of $N$. tenuis increased exponentially to reach a maximum of about $1.9 \pm 0.43$ and $3.0 \pm 0.4 \mathrm{~N}$. tenuis per leaf in compartments with low and high introduction rates of T. absoluta, respectively (Fig. 1). There were no significant differences in the number of $N$. tenuis in the treatments with low and high introduction rates of T. absoluta $(\mathrm{F}=1.06$; d.f. 1,$8 ; \mathrm{P}=0.334)$, and the interac- 


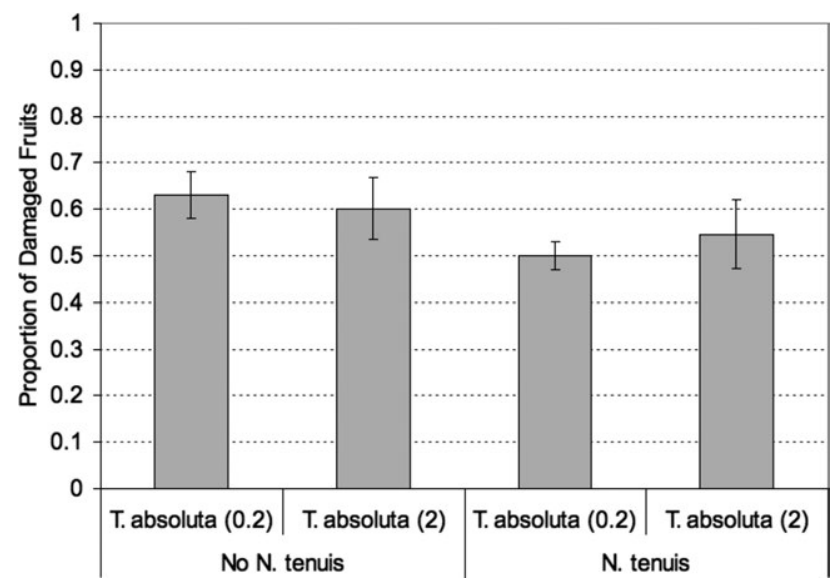

Fig. 6. Proportion of fruit damaged by Tuta absoluta in greenhouse compartments with and without $N$. tenuis and initially infested with either 0.2 or 2 larvae of $T$. absoluta per plant.

tion was not significant ( $\mathrm{F}=2.42$; d.f. 1,$8 ; \mathrm{P}=0.158)$. The number of $N$. tenuis was significantly higher in the compartments where it was released than in those where it was not $(\mathrm{F}=190.6$; d.f. 1,$8 ; \mathrm{P}<0.001)$. The population growth of $N$. tenuis paralleled that of T. absoluta. The cross correlation analyses showed a high correlation between the $N$. tenuis and T. absoluta time series, with correlation indexes ranging from 0.802 to 0.933 and time lags of $1-2$ weeks (Table 1). Lag times for $N$. tenuis and $D$. hesperus preying on whiteflies, estimated using previously published data, were about 4-5 weeks (Table 2). Fig. 3 shows the changes in population structure of $N$. tenuis with time. Adults of this mirid were generally recorded two weeks after the first release, but in very low numbers: $0.067 \pm 0.033$ and $0.133 \pm 0.110$ adults per plant in treatments with low and high introduction rates of T. absoluta, respectively (Fig. 3). The first $N$. tenuis nymphs were recorded in weeks 7-8. There were two peaks of increasing magnitude in the numbers of nymphs, the first in week 9 and second in weeks 13-14, followed by their respective peaks in the numbers of adults (Fig. 3). During the 12 weeks after its release $N$. tenuis completed two generations (Fig. 3).

The first necrotic rings were recorded in week 12 in the compartments where $N$. tenuis was released, and the incidence increased reaching a maximum of 0.06 and 0.1 per leaf in compartments with low and high introduction rates of T. absoluta, respectively (Fig. 4). There were no significant differences in the numbers of necrotic rings recorded in the treatments with low and high $T$. absoluta introduction rates $(\mathrm{F}=0.382$; d.f. 1,$4 ; \mathrm{P}=0.570)$. The total yield was higher in the treatments with than in those without $N$. tenuis $(\mathrm{F}=4.18$; d.f. 1,$8 ; \mathrm{P}=0.075)$, and was similar in the treatments with low and high introduction rates of $T$. absoluta $(\mathrm{F}=0.032$, d.f. $1,8, \mathrm{P}=0.862)$ (Fig. 5). The percentage of fruit damaged by $T$. absoluta was above $50 \%$ in all the treatments and there were no significant differences between the two $N$. tenuis treatments $(\mathrm{F}=2.61$, d.f. $1,8, \mathrm{P}=0.144)$, or between the treatments with low and high introduction rates of T. absoluta $(\mathrm{F}=0.432$, d.f. 1,8 , $\mathrm{P}=0.530$ ) (Fig. 6).

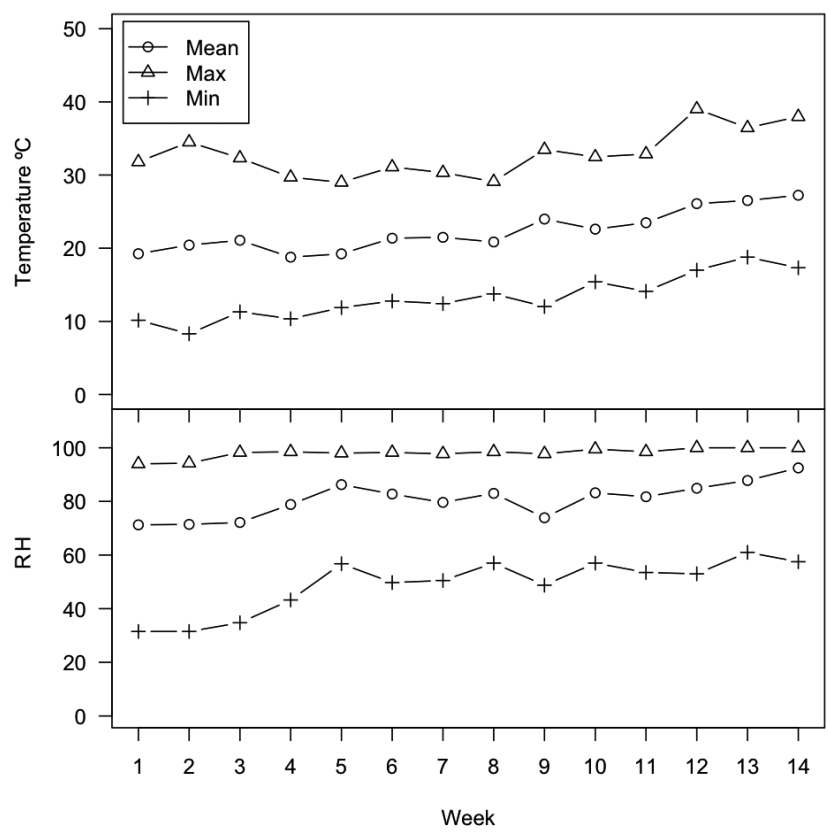

Fig. 7. Weekly average, maximum and minimum temperatures (upper graph), and relative humidity ( $\mathrm{RH}$ ) (lower graph) recorded during this study. $\mathrm{X}$ axis is the number of weeks after the infestation of the tomato plants with T. absoluta.

The average temperature ranged between $18.7^{\circ}$ to $21.1^{\circ} \mathrm{C}$ from week 1 to 5 ; from week 6 , the average temperature increased gradually and reached $27.2^{\circ} \mathrm{C}$ at the end of the experiment (Fig. 7). The minimum temperature increased gradually from $8.3^{\circ} \mathrm{C}$ in week 2 to $18.8^{\circ} \mathrm{C}$ in week 13 (Fig. 7). The maximum temperature was below $34^{\circ} \mathrm{C}$ from week 1 to 11 , and between $36^{\circ}$ and $39^{\circ} \mathrm{C}$ in the last three weeks (Fig. 7). The average RH ranged between 71 and 93\%, with high RH (close to $100 \%$ ) generally during the night and low RH (31-61\%) during the day (Fig. 7).

\section{DISCUSSION}

Nesidiocoris tenuis readily established itself on tomato plants infested with T. absoluta and its increase in abundance followed that of the moth. However, the numerical response of $N$. tenuis was not enough to keep T. absoluta below acceptable levels; the percentage of fruit damaged by $T$. absoluta was above $50 \%$ and not significantly different from that recorded in the control treatment without $N$. tenuis. There were no differences in the population dynamics of T. absoluta between treatments with low and high introduction rates, which might have been due to the high variation in the establishment of $T$. absoluta among the compartments, in light of the effect of stochastic factors on the survival of the larvae. Spraying with acetamiprid to prevent the spread of $N$. tenuis in compartments where it was not released produced a reduction in the number of $T$. absoluta. Although the active ingredient of this insecticide has a mild effect on T. absoluta, it still seems to have killed some of the T. absoluta larvae (Braham \& Hajji, 2012). The number of $T$. absoluta larvae on tomato plants was similar in the treatments with and without $N$. tenuis until the sixth week after the release of the predator, with differ- 
ences between treatments becoming noticeable in the following weeks. Nesidiocoris tenuis densities of about 0.2 individuals per leaf during the linear population growth phase of T. absoluta (approx. 0.5 to 3 larvae per leaf) were unable to prevent this pest from subsequently increasing exponentially. The lack of significant differences in the number of $T$. absoluta pupae and adults in the different treatments was probably due to the low precision of the sampling, as this species mainly pupates in the soil and only a small proportion of the pupae are found on leaves (Desneux et al., 2010), and adults are easily disturbed and difficult to count at high densities. The population structure of $N$. tenuis and cross correlation analyses indicate that the numerical response of the mirid was due to reproduction. Nesidiocoris tenuis completed two generations over a period of twelve weeks following its release. The initial population growth was due to the increase in the number of nymphs, which was followed by a small peak of adults and another two consecutive peaks of a much higher magnitude of nymphs and adults, respectively (Fig. 3). The lags between $N$. tenuis and T. absoluta larvae time series were 1-2 weeks (Table 1). These lags are very short considering the average temperature during the experiment $\left(22.7^{\circ} \mathrm{C}\right)$ and the time it takes the eggs of $N$. tenuis to hatch at $20^{\circ} \mathrm{C}$ (17 days) and $25^{\circ} \mathrm{C}$ (8.9 days), respectively (Sanchez et al., 2009). Therefore, it is likely that the increase in numbers of $N$. tenuis resulted from them mainly exploiting eggs and small larvae rather than feeding on T. absoluta larvae of all stages. This hypothesis is supported by the recorded higher incidence of predation on eggs and first instar larvae than on large larvae (Arnó et al., 2009; Urbaneja et al., 2009). The lags for $N$. tenuis and $D$. hesperus feeding on whiteflies are greater than those estimated for $N$. tenuis feeding on T. absoluta. Yoo \& O'Neil (2009) report that the weekly density of Orius insidiosus Say (Hemiptera: Anthocoridae) is significantly cross-correlated with the density of thrips in many fields, with lag times of 1-4 weeks.

The rapid numerical response of $N$. tenuis when $T$. $a b$ soluta was abundant indicates the suitability of $T$. absoluta as prey and is in accordance with the high rate of natural increase $\left(r_{m}\right)$ recorded for $N$. tenuis in laboratory experiments (Mollá et al., 2014). The slow population increase of $N$. tenuis in the initial phases may have been due to several reasons, among them natural emigration and/or high mortality, or a slow reproductive response of the mirid: (1) Natural emigration and/or high mortality due to scarcity of prey may have caused the decrease in the number of $N$. tenuis adults in the weeks following its release. Less than $10 \%$ percent of the adults released were recorded during sampling carried out in the two weeks following their introduction, while the expected mortality for this period on optimum food at that temperature $\left(20^{\circ} \mathrm{C}\right)$ is much lower (20\%) (Sanchez et al., 2009). Nannini et al. (2012) also indicate that it is likely that low prey availability is one of the factors responsible for the poor establishment of $N$. tenuis and $M$. pygmaeus in Sardinian tomato greenhouses. (2) The slow reproductive response of $N$. tenuis: the first $N$. tenuis nymphs were observed 5-6 weeks after the introduction of the adults, whereas, according to the expected egg-hatch time (17 days) at the temperature prevailing in greenhouses (approx. $20^{\circ} \mathrm{C}$ ) (Sanchez et al., 2009), nymphs should have been recorded in the third week after the release of the adults. This delay in the reproduction of the females may also be due to the scarcity of prey during the period of establishment. Laboratory studies indicate that the fecundity of omnivorous mirids is greatly reduced in the absence of prey (Perdikis \& Lykouressis, 2004; Sanchez et al., 2004). When T. absoluta was abundant, $N$. tenuis population growth was similar to that reported when it feeds on whitefly. When the number of T. absoluta was high (1.1-5.3 larvae and 0.04-0.01 adults per leaf), N. tenuis density increased from $0.13-0.39$ to $2.3-3.4$ individuals per leaf in five weeks. This increase indicates a population doubling time (DT) similar to the theoretical value estimated by Mollá et al. (2014) at $25^{\circ} \mathrm{C}$ in laboratory assays (7.8 days). In experiments carried out in southern Spain by Sanchez (2008) a population of $N$. tenuis feeding on whitefly increased from $0.17-0.6$ to $4.3-5.4$ in four weeks; the estimated DT for this increase (7.6-9.1 days) is also within the range of the theoretical value at $25^{\circ} \mathrm{C}$ (Mollà et al., 2013). Calvo et al. (2009) record a lower population growth rate for $N$. tenuis feeding on $B$. tabaci when $1 N$. tenuis per plant was released and similar population dynamics to that recorded in this study when 4 were released. The average temperatures recorded in these assays (Sanchez, 2008; Calvo et al., 2009) was higher than those recorded in the present study.

The results of the present study indicate that $N$. tenuis has a marked effect on the abundance of T. absoluta. This is an example of a generalist predator adapting to and regulating populations of exotic phytophagous species and taking advantage of pulsed resources to increase their populations (Ostfeld \& Keesing, 2000). However, there is a need for better levels of control of T. absoluta in commercial crops as it is very destructive. In the treatment without $N$. tenuis, tomato plants were almost completely destroyed when larvae reached densities of 23.7-79.3 per leaf in the last weeks of the experiment. At high densities, when all life stages of the moth are abundant, the preference of $N$. tenuis for eggs and first instar larvae (Arnó et al., 2009; Urbaneja et al., 2009) may reduce the predation pressure on the more voracious and destructive late-instar larvae. Other dicyphine species, such as M. pygmaeus and D. errans, also consume more eggs than larvae of T. absoluta and show higher preference for first-instar than bigger larvae (Urbaneja et al., 2009, Ingegno et al., 2013). In contrast, tomato plants may tolerate much higher whitefly densities without showing any noticeable damage. Calvo et al. (2009) report that $N$. tenuis is highly efficient in controlling $B$. tabaci as it can reduce the abundance of this pest by $81 \%-96 \%$ compared to the control; in spite of this, B. tabaci populations can reach densities of about 100 and 300 nymphs in treatments in which low or high numbers of the predator were introduced, respectively (Calvo et al., 2009). Similar reductions and density peaks for B. tabaci are recorded for tomato 
crops colonized naturally by $N$. tenuis without any apparent damage to the plants (Sanchez, 2008).

Due to the low damage threshold of tomato for T. absoluta, management strategies for $N$. tenuis are needed to build up its population before the moth colonizes this crop. One of the main limitations of using $N$. tenuis against T. absoluta is that it may take from five to eight weeks to reach the necessary number to achieve a good level of pest control, even under favourable conditions in spring-summer in southern Spain, while in unheated greenhouses in autumnwinter the mirid may never achieve high numbers (Mollá et al., 2011; Urbaneja et al., 2012). Strategies, in which $E$. kuehniella eggs are used as substitute prey to enable the predator to become established and increase in abundance prior to the arrival of pests, may accelerate the response of the predator and considerably reduce the incidence of pest outbreaks (Calvo et al., 2012a, b). Nesidiocoris tenuis can successfully control T. absoluta in tomato crops if it is well established at around one individual per leaf before the arrival of the pest (Calvo et al., 2012a). Releasing $N$. tenuis on tomato plants in nurseries before transplanting results in a good control of B. tabaci (Calvo et al., 2012b). Arnó et al. (2009) record low levels of fruit damage by T. absoluta in greenhouses where mirids are established at more than 4.5 individuals per plant. Independent of the good result, there is an evident implied risk in the above strategy, as N. tenuis may damage the crop if the increase in abundance promoted by artificial feeding is not associated with either an increase in the availability of prey (e.g. whitefly, T. absoluta) or additional feeding. Nesidiocoris tenuis is known to become more phytophagous and damage tomato plants at low prey densities (Sanchez et al., 2006; Sanchez \& Lacasa, 2008; Arnó et al., 2009, 2010; Calvo et al., 2009; Sanchez, 2009; Castañé et al., 2011). In the present study, necrotic rings were first recorded when the numbers of $T$. absoluta larvae and $N$. tenuis were 15 and 0.3 individuals per leaf, respectively. However, the incidence of necrotic rings was very low (0.06-0.1 rings per leaf) and in the range not associated with a loss of yield (Sanchez, 2009). The presence of alternative prey, in the same way as the addition of $E$. kuehniella eggs, may result in an increase in the numbers of $N$. tenuis, which might, in turn, reduce the abundance of T. absoluta. This is an example of what is known as "apparent competition", which predicts that two prey will have a lower density at equilibrium when they share a predator (Holt, 1977; van Veen et al., 2006). There are no examples of negative predator-mediated effects of secondary pests on T. absoluta, but there is evidence of the opposite effect. For instance, when M. pygmaeus is the shared predator, $T$. absoluta has a short-term positive effect and a long-term negative effect on the abundance of B. tabaci (Bompard et al., 2013).

The results of this study indicate that $N$. tenuis shows a numerical response to the abundance of $T$. absoluta on tomato crops. When $N$. tenuis was released after T. absoluta, the numerical response of the mirid was slow and did not keep the numbers of the moth below acceptable levels. Therefore, it is unlikely that $N$. tenuis will keep T. abso- luta at acceptable densities when the pest infests the crop before the predator arrives. According to the literature, $N$. tenuis can prevent an increase in the abundance of T. $a b$ soluta when climatic conditions are favourable and only when high numbers of the predator are present prior to the arrival of the pest. It is advisable to closely monitor both the predator (Sanchez, 2011) and the pest so that complementary control measures can be undertaken to prevent a $T$. absoluta outbreak when the numbers of predators are low and also prevent damage to plants by N.tenuis in the absence of prey. The use of alternative host plants as a source of predators has proved successful with other predatory mirids (e.g. D. hesperus) (Sanchez et al., 2003a) and might work with $N$. tenuis. Alternative host plants, such as Dittrichia viscosa (L.) (Asteraceae) (Sanchez et al., 2003b), might improve the stability of the system and the numerical response of the predator to prey on tomato plants by recruiting predators from the alternative host.

ACKNOWLEDGEMENTS. This work was funded by research projects INIA-CC09-048 and PO07-007 (FEDER). J.A. Sánchez was awarded grants by the Ministerio de Ciencia e Innovación (Ramón y Cajal program) and the European Social Fund. We thank A. Carrasco, M.C. Ortín-Ángulo, H. Ibáñez, E. López, I. García, A. López, A. García and I. Díaz for technical assistance. We are also grateful to two anonymous reviewers for their useful and inspiring comments.

\section{REFERENCES}

Alomar O. \& Albajes R. 1996: Greenhouse whitefly (Homoptera: Aleyrodidae) predation and tomato fruit injury by the zoophytophagous predator Dicyphus tamaninii (Heteroptera: Miridae). In Alomar O. \& Wiedenmann R.N. (eds): Zoophytophagous Heteroptera: Implications for Life History and Integrated Pest Management. Entomol. Soc. of America, Lanham, MD, pp. 155-177.

Arnó J., Sorribas R., Prat M., Matas M., Pozo C., Rodríguez D., Garreta A., Gómez A. \& Gabarra R. 2009: Tuta absoluta, a new pest in IPM tomatoes in the northeast of Spain. - IOBC WPRS Bull. 49: 203-208.

Arnó J., Castane C., Riudavets J. \& Gabarra R. 2010: Risk of damage to tomato crops by the generalist zoophytophagous predator Nesidiocoris tenuis (Reuter) (Hemiptera: Miridae). Bull. Entomol. Res. 100: 105-115.

Bielza P. 2010: La resistencia a insecticidas en Tuta absoluta. Phytoma 17: 103-106.

Bompard A., Jaworski C.C., Bearez P. \& Desneux N. 2013: Sharing a predator: can an invasive alien pest affect the predation on a local pest? - Popul. Ecol. 55: 433-440.

Braham M. \& HaJjI L. 2012: Management of Tuta absoluta (Lepidoptera, Gelechiidae) with insecticides on tomatoes. In Perveen F. (ed.): Agricultural and Biological Sciences, Insecticides - Pest Engineering, Tech, Rijeka, Croatia, pp. 333-354.

Cabello T., Gallego J.R., Fernández F.J., Gámez M.,Vila E., Del Pino M. \& Hernández-Suárez E. 2012: Biological control strategies for the south american tomato moth (Lepidoptera: Gelechiidae) in greenhouse tomatoes. - J. Econ. Entomol. 105: 2085-2096.

Calvo J., Bolckmans K. Stansly P.A. \& Urbaneja A. 2009: Predation by Nesidiocoris tenuis on Bemisia tabaci and injury to tomato. - BioControl 54: 237-246.

Calvo F.J., Lorente M.J., Stansly P.A. \& Belda J.E. 2012a: Preplant release of Nesidiocoris tenuis and supplementary tactics 
for control of Tuta absoluta and Bemisa tabaci in greenhouse tomato. - Entomol. Exp. Appl. 143: 1-9.

Calvo F.J., Bolckmans K. \& Belda J.E. 2012b: Release rate for a pre-plant application of Nesidiocoris tenuis for Bemisia tabaci control in tomato. - BioControl 57: 809-817.

Castañé C., Alomar O., Goula M. \& Gabarra R. 2004: Colonization of tomato greenhouses by the predatory mirid bugs Macrolophus caliginosus and Dicyphus tamaninii. - Biol. Contr. 30: 591-597.

Castañé C., Arnó J., Gabarra R. \& Alomar O. 2011: Plant damage to vegetable crops by zoophytophagous mirid predators. - Biol. Contr. 59: 22-29.

Crawley M.J. 2007: The R Book. John Wiley \& Sons, Chichester, viii $+942 \mathrm{pp}$

Desneux N., Wajnberg E., Wyckhuys K.A.G., Burgio G., Arpaia S., Narvaez-Vásquez C.A., González-Cabrera J., Ruescas D.C., Tabone E., Frandon J., Pizzol J., Poncet C., Cabello T. \& URBaneja A. 2010: Biological invasion of European tomato crops by Tuta absoluta: ecology, geographic expansion and prospects for biological control. - J. Pest Sci. 83: 197-215.

FitzGerald J. \& JAY C. 2011: Chemical control of the European tarnished plant bug, Lygus rugulipennis, on strawberry in the UK. - Crop Prot. 30: 1178-1183.

Gillespie D.R., McGregor R.R., Sanchez J.A., VanLaerhoven S.L., Quiring D.M.J., Roitberg B.D., Foottit R.G., Schwartz M.D. \& SHIPP J.L. 2007: An endemic omnivorous predator for the control of greenhouse pests. In Vincent C., Goettel M.S. \& Lazarovits G. (eds): Biological Control: A Global Perspective. CABI, Wallingford, pp. 128-135.

Goula M. \& Alomar O. 1994: Míridos (Heteroptera: Miridae) de interés en el control integrado de plagas en tomate. Guía para su identificación. Bol. Sanid. Veget. Plagas 20: 131-143.

HoLt R.D. 1977: Predation, apparent competition, and structure of prey communities. - Theor. Popul. Biol. 12: 197-229.

Ingegno B.L., Ferracini C., Gallinotti D., Alma A. \& Tavella L. 2013: Evaluation of the effectiveness of Dicyphus errans (Wolff) as predator of Tuta absoluta (Meyrick). - Biol. Contr. 67: 246-252.

Kim D.S., BRooks D.J. \& Riedl H. 2006: Lethal and sublethal effects of abamectin, spinosad, methoxyfenozide and acetamiprid on the predaceous plant bug Deraeocoris brevis in the laboratory. - BioControl 51: 465-484.

Lenfant C., Ridray G. \& Schoen L. 2000: Biopropagation of Macrolophus caliginosus Wagner for a quicker establishment in southern tomato greenhouses. - IOBC WPRS Bull. 23: $247-251$.

Lucas E. \& Alomar O. 2001: Macrolophus caliginosus (Wagner) as an intraguild prey for the zoophytophagous Dicyphus tamaninii Wagner (Heteroptera: Miridae). - Biol. Contr. 20: $147-152$.

LuCAS E. \& Alomar O. 2002: Impact of the presence of Dicyphus tamaninii Wagner (Heteroptera: Miridae) on whitefly (Homoptera: Aleyrodidae) predation by Macrolophus caliginosus (Wagner) (Heteroptera: Miridae). - Biol. Contr. 25: 123-128.

LuCAS E. \& RosenHeIM J.A. 2011: Influence of extraguild prey density on intraguild predation by heteropteran predators: A review of the evidence and a case study. - Biol. Contr. 59: 61-67.

Malausa J.C. \& Trottin-Caudal Y. 1996: Advances in the strategy of use of the predaceous bug Macrolophus caliginosus (Heteroptera: Miridae) in glasshouse crops. In Alomar O. \& Wiedenmann R.N. (eds): Zoophytophagous Heteroptera: Implications for Life History and Integrated Pest Management. Entomol. Soc. of America, Lanham, MD, pp. 178-189.
Mollá O., Montón H., Vanaclocha P., Beitia F. \& Urbaneja A. 2009: Predation by the mirids Nesidiocoris tenuis and Macrolophus pygmaeus on the tomato borer Tuta absoluta. - IOBC WPRS Bull. 49: 209-214.

Mollá O., González-Cabrera J. \& Urbaneja A. 2011: The combined use of Bacillus thuringiensis and Nesidiocoris tenuis against the tomato borer Tuta absoluta. - BioControl 56: 883-891.

Mollá O., Biondi A., Alonso-Valiente M. \& Urbaneja A. 2014: A comparative life history study of two mirid bugs preying on Tuta absoluta and Ephestia kuehniella eggs on tomato crops: implications for biological control. BioControl 57: 175-183.

NANNINI M. 2009: Preliminary evaluation of Macrolophus pygmaeus potential for control of Tuta absoluta. - IOBC WPRS Bull. 49: 215-218.

Nannini M., Atzori F., Murgia R.P. \& Sanna F. 2012: Use of predatory mirids for control of the tomato borer Tuta absoluta (Meyrick) in Sardinian greenhouse tomatoes. - EPPO Bull. 42: 255-259.

Ostfeld R.S. \& KeEsing F. 2000: Pulsed resources and community dynamics of consumers in terrestrial ecosystems. - Trends Ecol. Evol. 15: 232-237.

Perdikis D.C. \& LyKouressis D.P. 2004: Macrolophus pygmaeus (Hemiptera: Miridae) population parameters and biological characteristics when feeding on eggplant and tomato without prey. - J. Econ. Entomol. 97: 1291-1298.

Perdikis D.C., Kapaxidi E. \& Papadoulis G. 2008: Biological control of insect and mite pests in greenhouse solanaceous crops. - Eur. J. Plant Sci. Biotechnol. 2: 125-144.

R Development Core Team 2008: A Language and Environment for Statistical Computing. R Foundation for Statistical Computing, Vienna, Austria.

SANCHEZ J.A. 2008: Zoophytophagy in the plantbug Nesidiocoris tenuis. - Agric. Forest Entomol. 10: 75-80.

SAnchez J.A. 2009: Density thresholds for Nesidiocoris tenuis (Heteroptera: Miridae) in tomato crops. - Biol. Contr. 51: 493-498.

SANCHEZ J.A. 2011: Sampling of Nesidiocoris tenuis (Heteroptera: Miridae) in tomato crops. - Biocontr. Sci. Technol. 21: 1257-1261.

SANCheZ J.A. \& LaCASA A. 2008: Impact of the zoophytophagous plant bug Nesidiocoris tenuis (Heteroptera: Miridae) on tomato yield. - J. Econ. Entomol. 101: 1864-1870.

Sanchez J.A., Gillespie D.R. \& McGregor R.R. 2003a: The effects of mullein plants (Verbascum thapsus) on the population dynamics of Dicyphus hesperus (Heteroptera: Miridae) in tomato greenhouses. - Biol. Contr. 28: 313-319.

Sanchez J.A., Martínez-Cascales J.I. \& Lacasa A. 2003b: Abundance and wild host plants of predator mirids (Heteroptera: Miridae) in horticultural crops in the Southeast of Spain. - IOBC WPRS Bull. 26: 147-151.

SAnchez J.A., Gillespie D.R. \& McGregor R.R. 2004: Plant preference in relation to life history traits in the zoophytophagous predator Dicyphus hesperus. - Entomol. Exp. Appl. 112: 7-19.

Sanchez J.A., Pino-Pérez M., Davo M.M., Martínez-Cascales J.I. \& LACASA A. 2006: Zoophytophagy of the plantbug Nesidiocoris tenuis in tomato crops in southeast Spain. - IOBC WPRS Bull. 29: 243-248.

Sanchez J.A., Lacasa A., Arnó J., Castane C. \& Alomar O. 2009: Life history parameters for Nesidiocoris tenuis (Reuter) (Het., Miridae) under different temperature regimes. $-J$. Appl. Entomol. 133: 125-132.

Schun R.T. \& Slater J.A. 1995: True Bugs of the World. Cornell University Press, Ithaca, NY, xii +336 pp. 
Urbaneja A., Tapia G. \& Stansly P. 2005: Influence of host plant and prey availability on developmental time and survivorship of Nesidiocoris tenius (Het.: Miridae). - Biocontr. Sci. Technol. 15: 513-518.

Urbaneja A., Vercher R., Navarro V., García-Marí F. \& PorcuNA J.L. 2007: La polilla del tomate, Tuta absoluta. - Phytoma 194: $16-23$.

Urbaneja A., Montón H. \& Mollá O. 2009: Suitability of the tomato borer Tuta absoluta as prey for Macrolophus pygmaeus and Nesidiocoris tenuis. - J. Appl. Entomol. 133: 292-296.

Urbaneja A., González-Cabrera J., Arnó J. \& Gabarra R. 2012: Prospects for the biological control of Tuta absoluta in tomatoes of the Mediterranean basin. - Pest Manag. Sci. 68: $1215-1222$.
VAN DAM N.M. \& HARE J.D. 1998: Differences in distribution and performance of two sap-sucking herbivores on glandular and non-glandular Datura wrightii. - Ecol. Entomol. 23: 22-32.

van Veen F.J.F., Morris R.J. \& Godfray H.C.J. 2006. Apparent competition, quantitative food webs, and the structure of phytophagous insect communities. - Annu. Rev. Entomol. 51: 187-208.

Voigt D., Gorb E. \& Gorb S. 2007: Plant surface-bug interactions: Dicyphus errans stalking along trichomes. Arthr. Plant Interact. 1: 221-243.

Voigt D. \& Gorb S. 2010: Locomotion in a sticky terrain. - Arthr. Plant Interact. 4: 69-79.

Yoo H.J.S. \& O’Neil R.J. 2009: Temporal relationships between the generalist predator, Orius insidiosus, and its two major prey in soybean. - Biol. Contr. 48: 168-180.

Received September 13, 2013; revised and accepted March 7, 2014 Prepublished online April 23, 2014 